\title{
DIAGNÓSTICO DA GESTÃO DE RESÍDUOS SÓLIDOS NO TRANSPORTE HIDROVIÁRIO DO MUNICÍPIO DE BREVES (PA)
}

\author{
Manolo Cleiton Costa de Freitas ${ }^{1}$ \\ Tainara Demes Gonçalves ${ }^{2}$ \\ Cristiane Alves Barreto ${ }^{3}$ \\ Gabriela Barbosa dos Santos ${ }^{4}$
}

Ana Carolina Gomes de Albuquerque de Freitas ${ }^{5}$

Resumo: A cidade de Breves é cercada por vários rios que são o meio utilizado diariamente pela população para o transporte de cargas e passageiros. A gestão de resíduos sólidos nas embarcações de grande porte nas empresas de navegação, é uma problemática a ser estudada, pois é visível a destinação incorreta dos resíduos por funcionários e na maioria das vezes por passageiros das embarcações, causando impactos que trazem consigo várias consequências ambientais e sociais para a população da região. $O$ presente trabalho trata-se de uma pesquisa realizada nas empresas de transporte hidroviário do Município de Breves-PA. A pesquisa do tipo qualiquantitativo mediada por auxílio de questionários e entrevistas, teve como objetivo realizar um diagnóstico da gestão de resíduos sólidos com funcionários de três empresas de navegação, que prestam serviços no município, pois acredita-se que os funcionários podem ser disseminadores de informações e de novas condutas para os passageiros em relação à gestão de resíduos. A partir dos resultados obtidos pôde-se verificar a importância de se trabalhar a Educação Ambiental (EA). Além, de desenvolver projetos a serem aplicados no transporte hidroviário com foco na gestão de resíduos sólidos, visto que foi comprovado a carência de informação quanto à EA e à necessidade de ações nas embarcações voltadas para a temática.

Palavras-chave: Resíduos Sólidos; Educação Ambiental; Transporte hidroviário; Impactos ambientais.

\footnotetext{
1 Universidade Federal do Pará. E-mail: manolo@ufpa.br

2 Universidade Federal do Pará. E-mail: taydemes@gmail.com

3 Universidade Federal do Pará. E-mail: cristiane.barreto@breves.ufpa.br

${ }^{4}$ Universidade Federal do Pará. E-mail: gabrielabarbosagb143@gmail.com

${ }^{5}$ Universidade Federal do Sul e Sudeste do Pará. E-mail: albuquerqueacg@gmail.com

Revbea, São Paulo, V. 14, No 1: 222-244, 2019.
} 


\section{Introdução}

Poluição ambiental é um problema visivelmente grave que afeta de forma abrangente todo o território brasileiro. Em virtude disso, a sociedade vem buscando soluções para que esse problema, que compromete cada vez mais a qualidade de vida das pessoas, seja solucionado ou pelo menos minimizado.

A "cultura do lixo" está impregnada em toda sociedade, visto que, essa "cultura" já não gera o incômodo necessário para que se possa mudar a realidade. A Educação Ambiental (EA), de fato, é o ponto de partida para a mudança idealizada, pois, como esclarece Dias et al. (2016), "a EA deve, necessariamente, transformar-se em ação", disseminada [...] "mediante processos educativos que promovam a melhoria do meio ambiente e a qualidade de vida" (LEONARDI, 2002).

Também Loureiro et al. (2009) apud Oliveira et al. (2012), define e esclarece que na EA busca-se um novo comportamento do homem em relação a si mesmo e sua relação com o meio em que vive.

De acordo com Silva (2014), "é a partir dessa inserção da EA no processo educativo que a construção de valores, atitudes, habilidades $e$ competências" são estruturados para que, tanto o indivíduo, quanto a coletividade possam atuar de forma proativa na conservação do meio ambiente.

$\mathrm{Na}$ Lei Nacional da Educação Ambiental, o Art. $2^{\circ}$, pode-se ler que a "Educação Ambiental é um componente essencial e permanente da educação nacional, devendo estar presente, de forma articulada, em todos os níveis e modalidades do processo educativo, em caráter formal e não-formal' (BRASIL, 1999). Portanto, pode-se afirmar que a EA não deve ser trabalhada somente no âmbito escolar, todavia, deve ser trabalhada em vários segmentos da sociedade. Segundo Leonardi (2002), "a EA pode ser classificada dependendo do espaço (formal, não formal ou informal)", denomina-se modalidade formal aquela exercida como atividade escolar, sendo considerada mais usual. Já a modalidade não-formal é exercida em variados espaços da vida social e se caracteriza por ser realizada fora da sala de aula e da escola, coloca-se em contato com outros atores que também atuam com a questão ambiental, tanto no espaço público quanto privado. A informal também é realizada em outros e variados espaços da vida social, mas não exige sua forma de ação, metodologia e avaliação, por exemplo os meios de comunicação escrita e falada.

O Programa Nacional de Educação Ambiental - ProNEA criado em 2004, apresenta dentre os seus inúmeros objetivos "Fomentar processos de formação continuada em Educação Ambiental, formal e não-formal, dando condições para a atuação nos diversos setores da sociedade" (BRASIL, 2005).

Portanto, nota-se a relevância de planos para se trabalhar EA em os setores da sociedade, incluindo os empresariais. 
De acordo com o Plano de Desenvolvimento Territorial Sustentável do Arquipélago do Marajó, elaborado inicialmente em 2006 pelo Grupo Executivo Interministerial e formalizado pelo Estado do Pará por meio de Decreto Estadual em 30 de julho de 2007, o município de Breves está situado de forma integrada ao arquipélago do Marajó (PARÁ, 2007).

A cidade de Breves-PA, com uma população de 99.080 habitantes ocupando uma área de 9.563,007 km2 (IBGE, 2016), é cercada de vários rios que são as vias de transporte normalmente utilizadas. De acordo com o Plano Ambiental Municipal de 2012, a hidrografia do município tem um sistema de drenagem variado, apresentando furos, igarapés, paranás, lagos e rios caudalosos.

Diante da condição geográfica da região do Marajó onde localiza-se o município de Breves-PA, o meio de transporte mais utilizado é a navegação fluvial pela população em geral, feita por embarcações de grande, médio e pequeno porte como barcos, navios ou balsas, uma vez que se configura como meio de transporte diário de passageiros e cargas, movimentando a economia da região.

A gestão de resíduos sólidos no setor de transportes do município de Breves é uma problemática a ser levantada e estudada, pois, é visível a destinação incorreta dos resíduos feita por parte dos passageiros, em sua maioria e por funcionários das embarcações. Isso pode estar relacionado com a carência de informação quanto à preservação dos recursos hídricos, causando vários danos ambientais. A falta de conhecimento necessário sobre as consequências ambientais e econômicas causados pela destinação dos resíduos na água, afetam diretamente a tripulação, passageiros da embarcação e a população da região que utilizam dessa água. De acordo com Regueira e Guenther (2014), os resíduos sólidos que têm por destino final a água, acabam gerando vários problemas ambientais e, consequentemente, sociais para a população que utiliza os recursos hídricos.

De acordo com Santana (2008), a Marinha do Brasil estabelece, por meio da Lei 9.537 de 11 de dezembro de 1997, conhecida como "LESTA - Lei de Segurança do Tráfego Aquaviário", os princípios gerais para o tráfego aquaviário (marítimo, fluvial, lacustre), a segurança da navegação, a salvaguarda da vida humana e a preservação do meio ambiente hídrico.

Segundo Valle (1995 apud SANTANA, 2008), a contaminação das águas é, portanto, uma das maiores preocupações dos ecologistas e de todos aqueles que necessitam utilizá-la como insumo em atividades econômicas. Contudo, o homem é prejudicado diretamente com este tipo de ação.

Nas empresas de navegação do Município de Breves é nítida a importância de se trabalhar a EA, desenvolver projetos a serem aplicados no transporte hidroviário com foco na gestão dos resíduos sólidos. Portanto, a gestão de resíduos nos transportes fluviais é importante para se ter a destinação correta dos resíduos e ter o controle, de forma que esses resíduos não sejam lançados pela tripulação e passageiros nos rios.

Revbea, São Paulo, V. 14, № 1: 222-244, 2019. 
Diante do exposto, este trabalho surgiu a partir dos seguintes questionamentos "como é a gestão de resíduos no transporte hidroviário?" e "as empresas de navegação do município de Breves possuem algum projeto sobre EA que trabalhe com os seus funcionários?'. Este segundo questionamento é o mais importante, pois os funcionários podem ser os disseminadores de informação de forma a evitar a poluição dos rios por parte dos passageiros. Outro questionamento é "se seguem uma legislação específica do Município ou a Política Nacional de Resíduos Sólidos?", pois cabe ressaltar que a Lei Ambiental do Município de Breves, capítulo III, art. 8º, preconiza que o município deve estabelecer normas de controle da poluição do solo, ar, sonora, de suas águas [...] e de transportes. Ou ainda "se possuem algum projeto para tratar os resíduos sólidos?". E somado a isso, se o poder público municipal está fazendo sua parte por meio da Secretaria Municipal de Meio Ambiente, dando apoio realizando campanhas e ações sobre EA e gestão de resíduos nas empresas de navegação.

\section{Referencial Teórico}

\section{Definição de Resíduos Sólidos}

Segundo Ferreira (2008), "lixo é qualquer objeto ou detrito que se joga fora, ou se varre de casa, da rua, etc., coisa imprestável". O autor afirma que lixo é todo e qualquer resíduo resultante de atividades humanas, como atividades domésticas, hospitalares, industriais, comerciais etc.

Fazendo uma reflexão sobre o conceito e contexto ao qual o termo lixo é empregado, cabe ressaltar que quem julga que algo não lhe serve mais é o próprio gerador do resíduo. Diante disso, não cabe somente ao autor afirmar que lixo é "coisa imprestável" já que pode ser facilmente e muito bem reutilizado, pelo seu usuário. Portanto, mediante ao conceito superficial do termo lixo, ajusta-se a ele uma linguagem técnica, já que julgamentos pessoais não comprovam fatos científicos.

A Política Nacional de Resíduos Sólidos (PNRS) define rejeito como sendo "resíduos sólidos que, depois de esgotadas todas as possibilidades de tratamento e recuperação por processos tecnológicos disponíveis e economicamente viáveis, não apresentem outra possibilidade que não a disposição final ambientalmente adequada" (BRASIL, 2012).

A Resolução do Conselho Nacional do Meio Ambiente (CONAMA) № 5 , de 05 de agosto de 1993, no Art. 1ㅜㄹ. Inc. I, define os resíduos sólidos como: "Resíduos nos estados sólido e semissólido, que resultam de atividades da comunidade de origem: industrial, doméstica, hospitalar, comercial, agrícola, de serviços e de varrição. (...)." (Resoluções do CONAMA, 2012).

De acordo com o ambientalista Paulo Affonso Lemes Machado, "o termo resíduo sólido como entendemos no Brasil, significa lixo, refugo e outras descargas de materiais sólidos, incluindo materiais sólidos e materiais 
provenientes de operações industriais, comerciais e agrícolas e de atividades da comunidade" (MACHADO, 2007, apud, SILVA, 2015).

Os resíduos podem ser classificados de acordo com seu tipo, podendo ser reciclável como o plástico, metal, alumínio, papel. Também podem ser do tipo não reciclável, por exemplo, restos de comida, cascas e bagaços de frutas e verduras, alimentos estragados etc., ou rejeitos, que são resíduos recicláveis contaminados.

Pode-se classificar a periculosidade de um resíduo de acordo com ABNT (2004), segundo suas propriedades, físicas, químicas ou infectocontagiosas. Essas características podem apresentar risco à saúde pública, provocando mortalidade, incidência de doenças ou acentuando seus índices. Além disso, riscos ao meio ambiente, quando o resíduo for gerenciado de forma inadequada. Ou seja, resíduos perigosos são aqueles que podem apresentar riscos para a população ou para o meio ambiente.

Segundo o Plano Nacional de Resíduos Sólidos, os resíduos gerados pelos serviços de transportes aquaviário, são de natureza diversa, como ferragens, resíduos de cozinha, lâmpadas, pilhas, etc.

Entre os principais portos brasileiros, de acordo com Azevedo (2007) apud Brasil (2012), verificou-se que os resíduos gerados são de:

Naturezas diversas, tais como ferragens; resíduos de cozinha, do refeitório, dos serviços de bordo; óleos; resíduos orgânicos; resíduos químicos; material de escritório; resíduos infectantes; cargas em perdimento, apreendidas ou mal acondicionadas; sucatas; papel/papelão; vidro, plásticos e embalagens em geral; resíduo sólido contaminado de óleo; resíduo aquoso contaminado com óleo; pilhas e baterias; lâmpadas, acúmulo de grãos; resíduos resultantes das operações de manutenção do navio (embalagens, estopas, panos, papéis, papelão, serragem) ou provenientes da mistura de água de condensação com óleo combustível (AZEVEDO, 2007 apud BRASIL, 2012).

De acordo com Martins e More (2012), a Lei № 8.630/1993 (Lei de Modernização dos Portos) define como competências do administrador portuário a responsabilidade pela fiscalização das operações portuárias, zelando para que os serviços se realizem com regularidade, eficiência, segurança e respeito ao meio ambiente.

Segundo a Agência Nacional de Transporte Aquaviários - ANTAQ, responsável pela regulamentação, controle tarifário, estudo e desenvolvimento do transporte aquaviário no Brasil, pela resolução № 2190 de 28 julho de 2011 , no Art. $2^{\circ}$ Inc. IV, define os resíduos de embarcação como: 
Resíduos sólidos, semissólidos ou pastosos, e líquidos gerados durante a operação normal da embarcação, tais como: resíduo hospitalar ou de saúde, água de lastro suja, água oleosa de porão, mistura oleosa contendo químicos, resíduos oleosos (borra), água com óleo resultante de lavagem de tanques, crosta e borra resultantes da raspagem de tanques, substâncias químicas líquidas nocivas, esgoto e águas servidas, lixo doméstico operacional, resíduos de limpeza de sistemas de exaustão de gases e substâncias redutoras da camada de ozônio (BRASIL, 2011).

Nesse sentindo, a adequada gestão de resíduos nos portos e embarcações é fundamental para a empresa e população, visto que, o mal gerenciamento dos resíduos sólidos está relacionado a riscos ambientais, riscos à saúde humana e às saúdes da fauna e flora atingida por tal problema.

\section{A Política Nacional de Resíduos Sólidos - PNRS}

No transporte hidroviário faz-se necessário a lei de gerenciamento de resíduos sólidos, a fim de, assegurar sua destinação correta, evitando a poluição dos rios, e consequentemente evitando diversos impactos ambientais. $\mathrm{Na}$ Política Nacional de Resíduos Sólidos - PNRS, Lei № 12.305/2010, regulamentada pelo Decreto № 7.404, pode-se observar que um dos seus objetivos descrito no Art. $7^{\circ}$ é a "proteção da saúde pública e da qualidade ambiental" (BRASIL, 2012). Antes da instituição da PNRS "a gestão de resíduos era orientada por instrumentos legais e de regulação isolados". Com o advento da nova lei, "ganharam destaque questões relativas à gestão integrada e responsabilidade compartilhada" (MARTINS; MORE, 2012).

Observa-se na PNRS, entre seus princípios e objetivos, questões relacionadas à gestão integrada com Estados, Municípios e empresas privadas sobre gerenciamento ambientalmente adequado dos resíduos sólidos. Conforme a PNRS pode-se definir gestão integrada de resíduos sólidos como: "conjunto de ações voltadas para a busca de soluções para os resíduos sólidos, de forma a considerar as dimensões política, econômica, ambiental, cultural e social, com controle social e sob a premissa do desenvolvimento sustentável' (BRASIL, 2012).

De acordo com o Art. 9ํำ da PNRS, para a adequada operacionalização da gestão e gerenciamento de resíduos sólidos, deve-se observar a seguinte ordem de prioridade: não geração, redução, reutilização, reciclagem, tratamento dos resíduos sólidos, bem como disposição final ambientalmente adequada dos rejeitos.

Nesta mesma resolução no Art. 1ํ, Inc. I, pode-se ler que: 
Estão sujeitas à observância desta lei as pessoas físicas ou jurídicas, de direito público ou privado, responsáveis, direta ou indiretamente, pela geração de resíduos sólidos e as que desenvolvam ações relacionadas à gestão integrada ou ao gerenciamento de resíduos sólidos (BRASIL, 2012).

A partir da PNRS foi criada o Plano Nacional de Resíduos Sólidos com o objetivo de contemplar a problemática dos diversos tipos de resíduos gerados, as alternativas de gestão e gerenciamento, planos de metas, programas, projetos e ações.

Os resíduos sólidos ganharam uma classificação no Art. 13ํำ da PNRS, que permite uma padronização das políticas Estaduais e Municipais, e dos planos de gestão de resíduos sólidos nos empreendimentos, inclusive originário de portos.

O Plano Diretor Participativo do Município de Breves 2011- 2020 no Art. 74ํㅡ, lê-se que "o programa de coleta e destinação final de resíduos sólidos tem por objetivo desenvolver um ciclo sustentável, que inclui a coleta seletiva, o seu aproveitamento, reaproveitamento ou reciclagem, quando for o caso e o tratamento de sua destinação final'. Porém, segundo a Secretaria Municipal de Obras (SEOB), o município não tem coleta seletiva, pois, não possui estrutura para desenvolver essa ação.

A prefeitura municipal de Breves por meio da Lei Federal № 12.305, que institui a PNRS elaborou por meio do decreto № 056 , de 31 de julho de 2012, o Plano Municipal Integrado de Resíduos Sólidos de Breves, devendo este ser atualizado a cada quatro anos. Dentre seus vários objetivos, destacase redução, reaproveitamento e gerenciamento adequado dos resíduos sólidos; prevenção e controle da poluição; proteção e recuperação da qualidade do meio ambiente e promoção da saúde pública, assegurando o uso adequado dos recursos ambientais no Município. A Secretaria Municipal de Meio Ambiente - SEMMA, segundo o Plano relatado anteriormente, é a responsável também em promover programas e ações para que os objetivos sejam alcançados.

Na Lei Ambiental № 2.247/2012 da política Municipal de Gestão Ambiental do Município de Breves, no Art. 8o, lê-se que o Município deve estabelecer o controle da poluição da água pela utilização ecologicamente adequada, respeitando as condições ambientais, de trechos navegáveis dos rios e igarapés para atividades econômicas e/ou de valorização destes (turismo, pesca e transporte);

Segundo a SEMMA, foi elaborado no ano de 2017 o Plano Municipal de Educação Ambiental, que contempla projetos que combatem a todo e qualquer tipo de degradação ambiental. Ainda de acordo com a SEMMA, dentre esses projetos que contemplam o Plano está incluso o projeto de proteção e preservação dos rios e igarapés do Município de Breves, cujo objetivo é "Sensibilizar a comunidade em geral, quanto à preservação das 
águas dos rios marajoaras, com o interesse de mantê-las apropriadas para o consumo". O mesmo é composto de várias ações, dentre elas, palestras, roda de conversas junto a empresas e funcionários de empresas de navegação de pequeno, médio e grande porte, orientação verbal, distribuição de adesivos informativos, com foco na preservação de recursos hídricos e gestão de resíduos sólidos a embarcações ancoradas em toda extensão da orla do Município. A questão é se de fato, o projeto está sendo realizado na prática, mas isso será comprovado mais a frente no decorrer do trabalho.

\section{Metodologia}

\section{O Lócus da Pesquisa}

A pesquisa de campo foi realizada no Município de Breves nas três mais conhecidas e utilizadas empresas de navegação do município. A coleta de dados teve como público-alvo os funcionários das empresas que fazem transporte de cargas e passageiros para outras cidades. A amostragem alcançada foi setenta e um funcionários, que englobam a tripulação das oito embarcações, além dos funcionários fixos dos portos. A investigação foi realizada no período de outubro a dezembro de 2017.

A pesquisa tem abordagem de cunho qualitativo e quantitativo, pois "a utilização conjunta da pesquisa qualitativa e quantitativa permite recolher mais informações do que se poderia conseguir isoladamente" (FONSECA, 2002).

De acordo com Gerhardt e Silveira (2009), "a pesquisa qualitativa se aprofunda na compreensão de um grupo social ou organização, fazendo reflexão sobre motivos, atitude e valores que levam as pessoas a agirem de uma determinada forma". Para a análise dos dados qualitativos, amparou-se nos pressupostos da Análise Textual Discursiva (ATD), que é definida pela busca da compreensão mais profunda de elementos investigados, e busca pela compreensão de como ocorrem certos fatos em várias áreas do conhecimento. E que cada vez mais este tipo de metodologia está sendo empregada aos mais diversificados temas do cotidiano, inclusive em EA (MORAES, 2003).

Também foram quantificados os resultados da amostragem com setenta e um funcionários, que representam o público-alvo da pesquisa, pois segundo Fonseca (2002), "a pesquisa quantitativa influenciada pelo positivismo, considera, que a realidade só pode ser compreendida com base na análise de dados brutos".

Utilizou-se na pesquisa o método de análise de conteúdo, pois de acordo com Gerhardt e Silveira (2009), essa técnica permite ao pesquisador analisar, compreender e interpretar os dados coletados, ou seja, penetrar nos significados que os atores sociais compartilham na vivência da sua realidade. Para isso, foi utilizado o método de análise estatística dos dados, para o processamento e obtenção dos resultados da pesquisa. Os resultados da pesquisa foram quantificados e descritos de forma numérica. Para a apresentação, os dados coletados foram organizados através de gráficos e tabelas, para melhor compreensão.

revista brasileira educação ambiental 


\section{Coleta de Dados}

Na primeira etapa do trabalho foram utilizadas fontes bibliográficas que serviram como base para o desenvolvimento do seu referencial teórico. A pesquisa foi realizada por meio de questionários e entrevista estruturada, ambos aplicados aos funcionários das embarcações, pois acredita-se que os funcionários são a base para conhecer a dinâmica da empresa em relação ao que se quer analisar. $O$ questionário foi composto por dez perguntas mistas (abertas e fechadas), nele foram feitas referências ao conhecimento sobre EA, se o sujeito da pesquisa em questão por algum momento já destinou algum resíduo nos rios durante as viagens ou observou algum passageiro tendo essa atitude, ou ainda, se sabem das consequências dessas atitudes, entre outras perguntas. Com os representantes da parte administrativa das empresas foco da pesquisa, foram feitas entrevistas com roteiro perspectivo aberto, para conhecer a dinâmica da empresa de embarcação em relação à EA e gestão de resíduos sólidos. A mesma metodologia foi utilizada para realização da entrevista feita com a secretária da SEMMA.

\section{Resultados}

É de extrema importância fazer um levantamento de dados para diagnosticar e desenvolver projetos futuros sobre EA e sua efetiva funcionalidade nas empresas de navegação do Município de Breves, em relação aos resíduos sólidos. Para tal, buscou-se informações em diferentes órgãos municipais como a Secretaria Municipal de Meio Ambiente - SEMMA, Secretaria Municipal de Obras - SEOB, além de informações sobre Leis Municipais no que diz respeito aos resíduos sólidos, a fim de obter resultados, levantar questões e reflexões sobre a gestão de resíduos feita pelas empresas. $\mathrm{E}$ em especial, sobre a carência de se trabalhar a EA com os funcionários e passageiros, levando-se em consideração a ausência de sua prática durante as viagens nas embarcações.

A identidade das empresas de navegação foi mantida em sigilo. Por este motivo os resultados serão apresentados pela seguinte denominação: "empresa A, empresa B e empresa C", e serão apontados, a seguir, os aspectos gerais das respostas dos funcionários das três empresas foco da pesquisa.

\section{Aspectos Gerais das Respostas os funcionários}

Responderam ao questionário o total de setenta e um funcionários nas três empresas de navegação do Município de Breves. Na Figura 1, pode-se verificar os percentuais dos entrevistados, considerando todo o universo amostral pesquisado. 


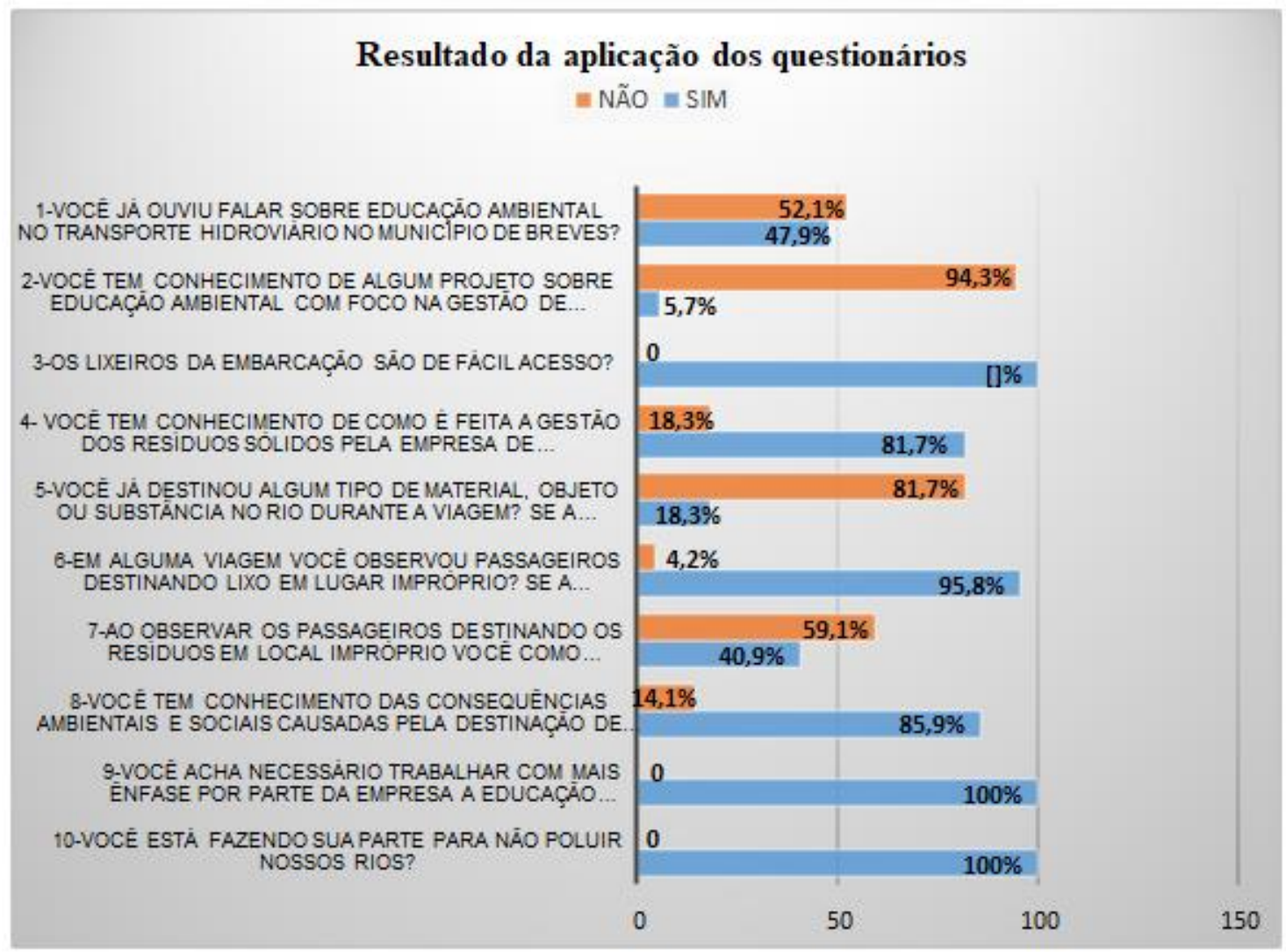

Figura 1: Percentual de todos os funcionários das empresas.

Fonte: Dados produzidos pelo autor.

Com relação à primeira pergunta, nota-se a partir dos resultados da pesquisa presente na Figura 1 , que mais da metade dos funcionários entrevistados, cerca $(52,1 \%)$ não ouviram falar sobre EA no transporte hidroviário, logo percebe-se a necessidade de mais informação sobre a temática, pois segundo o capítulo III da Lei Ambiental № 2.247/2012 do Município de Breves "a Educação Ambiental deve ser promovida tanto na rede de ensino, assim como para todos os segmentos da sociedade".

O resultado da segunda pergunta causa preocupação, pois $(94,3 \%)$ dos funcionários não têm conhecimento sobre projeto de EA com foco na gestão de resíduos sólidos gerados pelos usuários e funcionários das empresas de navegação. A gerência de uma das empresas foco da pesquisa, respondeu em entrevista que possui projeto de EA, porém não descreveu nada além disso, por este motivo não foi possível analisá-lo de forma clara e se de fato este é aplicado.

$\mathrm{Na}$ terceira pergunta, percebeu-se que o problema da destinação de resíduos não é por difícil acesso aos cestos para depósitos de lixo, pois todos os funcionários das empresas afirmaram que os lixeiros das embarcações são de fácil acesso; o problema é de sensibilização e conscientização de fato por parte dos usuários, visto que uma das formas destes "adquirirem consciência, 
conhecimentos e habilidades necessárias à melhoria de sua qualidade de vida é por meio da Educação Ambiental" (UNESCO, 2013 apud SILVA, 2014).

$\mathrm{Na}$ quarta pergunta, nota-se que a maioria dos funcionários entrevistados $(81,7 \%)$ das três empresas, têm conhecimento básico de como é feita a gestão de resíduos; em conversa informal esclareceram que a gestão se resume em fazer a limpeza dos resíduos dos cestos de lixo, dos resíduos destinados pelos usuários no convés das embarcações e, em seguida, são deixados no depósito à espera do caminhão coletor de lixo da prefeitura. Em relatório à Secretaria Municipal de Obras e Serviços Urbanos - SEOB, esclareceu que trabalha com dois caminhões papa-lixo e fazem a coleta nos dias úteis dos resíduos das empresas.

$\mathrm{Na}$ quinta pergunta, a maioria dos funcionários afirmou não destinar nenhum tipo de resíduo nos rios durante as viagens; mais precisamente $82,7 \%$ dos funcionários responderam não. Dos 18,3\% funcionários que responderam sim, justificaram em sua atitude por "cultura ou costume".

$\mathrm{Na}$ sexta pergunta, comprova-se o agravante e justifica-se este trabalho, pois $95,8 \%$ dos funcionários entrevistados afirmou observar passageiros destinando resíduos em lugar impróprio.

$\mathrm{Na}$ Tabela 1, nota-se que 34 dos 71 funcionários entrevistados afirmaram observar passageiros destinando resíduos nos rios. O grupo de 22 dos funcionários afirmou observar passageiros destinando no convés das embarcações; no entanto, 15 dos 71 funcionários não observaram os passageiros destinando resíduos em local impróprio.

Tabela 1: Dados gerais da quinta pergunta.

\begin{tabular}{ll}
\hline \multicolumn{1}{c}{ TOTAL DE FUNCIONÁRIOS } & $\mathbf{7 1}$ \\
\hline Destino de resíduos no rio. & 34 \\
\hline Destino de resíduos no convés. & 22 \\
\hline Não observaram. & 15 \\
\hline
\end{tabular}

Fonte: Dados obtidos pelo autor.

Percebe-se por meio das respostas obtidas, que o destino dos resíduos sólidos da maioria dos passageiros, segundo a observação dos funcionários das empresas, é os rios durante as viagens. Na Lei Ambiental do Município de Breves no Art. $3^{\circ}$ Inc. III, pode-se ler dentre seus objetivos "a promoção da integridade das águas superficiais e subterrâneas do território do município, através de ação articulada com as políticas estadual e federal de recursos hídricos". Portanto, observa-se que um dos objetivos da referida Lei é manter a integridade dos recursos hídricos do município.

Em relação à sétima pergunta, percebe-se que $59,1 \%$ dos funcionários não interviu ao observar passageiros destinando resíduo em local impróprio, pois segundo os mesmos, essa atitude pode não ser bem vista pelo passageiro, por isso eles têm receio em intervir. Dos 40,9\% funcionários que 
chamou atenção quando observaram passageiros destinando resíduo em local impróprio, quando perguntados se essa atitude foi orientação por parte da empresa, alguns responderam que foi por orientação da CIABA - Centro de Instrução Almirante Braz Aguiar no curso para Aquaviário e outros responderam que foi por conhecimento trazidos da escola com relação às consequências da destinação incorreta dos resíduos.

$\mathrm{Na}$ oitava pergunta, observa-se que $85,9 \%$ dos funcionários entrevistados afirmou saber das consequências ambientais e sociais causadas pela destinação de lixo nos rios. Apenas $14,1 \%$ dos funcionários não tem conhecimento sobre os impactos ambientais, entretanto, a partir do resultado percentual, observa-se a necessidade de maior informação sobre essa questão.

Pelo resultado da nona pergunta, entende-se a urgência e necessidade das empresas trabalharem a EA com seus funcionários, tendo apoio municipal para que, por meio da sensibilização de todos, haja a mudança de atitude para surtir resultados significativos e positivos com relação à gestão de resíduos. Todos os funcionários afirmaram achar necessário trabalhar a EA com foco na gestão de resíduos. Quando indagadas sobre essa questão, as gerências das empresas afirmaram que necessitam de apoio municipal para realizar essas ações, alegando não existir até então.

A décima pergunta do questionário, foi pensada objetivando gerar nos funcionários, uma reflexão sobre suas atitudes, se estes estão fazendo a parte deles no que se refere ao combate à poluição dos rios. O resultado foi positivo: $100 \%$ dos funcionários responderam que sim. Se fazem de fato, não se pode afirmar na prática, entretanto, permite, por meio dessa pergunta, que eles reflitam e percebam se há a necessidade de mudança de suas atitudes para não poluir, isso já é um bom incentivo à mudança.

\section{Empresa "A"}

A empresa trabalha com quatro embarcações atualmente, dois catamarãs que fazem rota pelas cidades de Belém, Barcarena, Ponta Negra, Conceição, São Sebastião da Boa Vista, Curralinho, Araras e Breves. E dois navios que fazem rota por Curralinho, Araras, Breves, Melgaço e Portel.

Os resíduos sólidos produzidos durante as viagens são destinados somente na cidade de Breves e Belém. Segundo a gerência da empresa, por meio de entrevista transcrita, desconhece a PNRS ou alguma lei específica do município com relação à preservação do meio ambiente hídrico e à gestão de resíduos sólidos. Entretanto, existe a Lei Ambiental do município que evidencia, dentre seus objetivos, "a integridade das águas". Além disso, o município de Breves por meio do decreto № 056, aprovou em 2012 o Plano Municipal Integrado de Resíduos Sólidos, onde pode-se ler, no Art. 1ํInc. VIII, que um dos seus objetivos é "prevenir e corrigir os impactos ambientais causadas pelos resíduos".

revista brasileira educação ambiental 
Não há nas embarcações coleta seletiva, visto que a empresa alega que os passageiros não faziam a separação no momento da destinação do lixo no seu devido coletor, além disso, acrescentou a gerência, citando que o município não realiza esse trabalho quando o lixo é coletado pelo "carro coletor de lixo". Porém, segundo a Lei Ambiental do Município de Breves em seu Art. 3o Inc. VII que tem como objetivo a ser competido o acondicionamento, armazenamento, coleta, transporte, reciclagem, tratamento e a disposição final dos resíduos sólidos. Também o Plano Municipal Integrado de resíduos sólidos no Art. $1^{\circ}$ Inc. VII, lê-se o objetivo de fomentar a reutilização, a recuperação, a reciclagem e a valorização dos resíduos, o que se observa segundo a resposta da gerência da empresa, ambos objetivos não estão sendo atingidos na prática.

A empresa não possui nenhum projeto para tratar os resíduos sólidos produzidos durante as viagens, justificando que desconhece trabalhos do município em relação ao lixo, alegando que não existe nenhuma política do município com foco nessa questão. Entretanto, no Art. $1^{\circ}$ da Lei Ambiental Municipal, observa-se dentre seus princípios "a defesa, conservação, preservação e recuperação da qualidade e salubridade ambiental, cabendo a todos os cidadãos o direito de exigir a adoção de medidas neste sentido". A empresa não possui nenhum projeto de EA com foco na gestão de resíduos sólidos que seja trabalhado com seus funcionários. De acordo com a gerência, seria essencial trabalhar a EA e gestão de resíduos com os funcionários, porém, a gerência esclarece: "devido não ter um trabalho em relação ao lixo, não existe município, a nossa maior preocupação com o lixo dos navios e catamarãs é o passageiro jogar o lixo no rio, apesar de ter assistido várias cenas de passageiros com um grau de formação elevado jogar o lixo no rio". Quando perguntado se os funcionários são orientados a intervir quando observam passageiros destinando resíduos em local impróprio, a resposta foi: "nem pensar, porque os passageiros não entenderiam", ou seja, a empresa tem receio de perder o cliente. De acordo com a gerência, falta consciência por parte dos passageiros, visto que, muitas vezes os cestos de lixo estão ao lado e acabam jogando o lixo em locais inadequados.

Responderam ao questionário o total de trinta e três funcionários da empresa "A". Os resultados da coleta de dados estão descritos na Figura 2.

$\mathrm{Na}$ primeira pergunta, observa-se a que a maioria dos funcionários $(66,6 \%)$ da empresa "A" não ouviu falar sobre EA no transporte hidroviário no Município de Breves. Na segunda pergunta, todos os funcionários não têm conhecimento sobre nenhum projeto de EA, com foco na gestão de resíduos sólidos realizado pela empresa, pois de fato, a empresa não possui nenhum projeto voltado para esta temática. Na terceira pergunta, todos os funcionários afirmaram que os cestos para o lixo das embarcações da empresa são de fácil acesso, o que comprova que o motivo da destinação incorreta dos resíduos não é por falta de depósitos de lixo. $\mathrm{Na}$ quarta pergunta, $72,2 \%$ dos funcionários afirmou saber como é feita a gestão de resíduos sólidos realizada pela empresa. Na quinta pergunta, $84,8 \%$ dos funcionários negou destinar 
resíduos nos rios, $15,2 \%$ dos funcionários que afirmou destinar resíduos nos rios, todos justificaram, descrevendo que é uma atitude "cultural ou costume", como disse um funcionário: "às vezes a gente acaba jogando por falta de atenção mesmo".

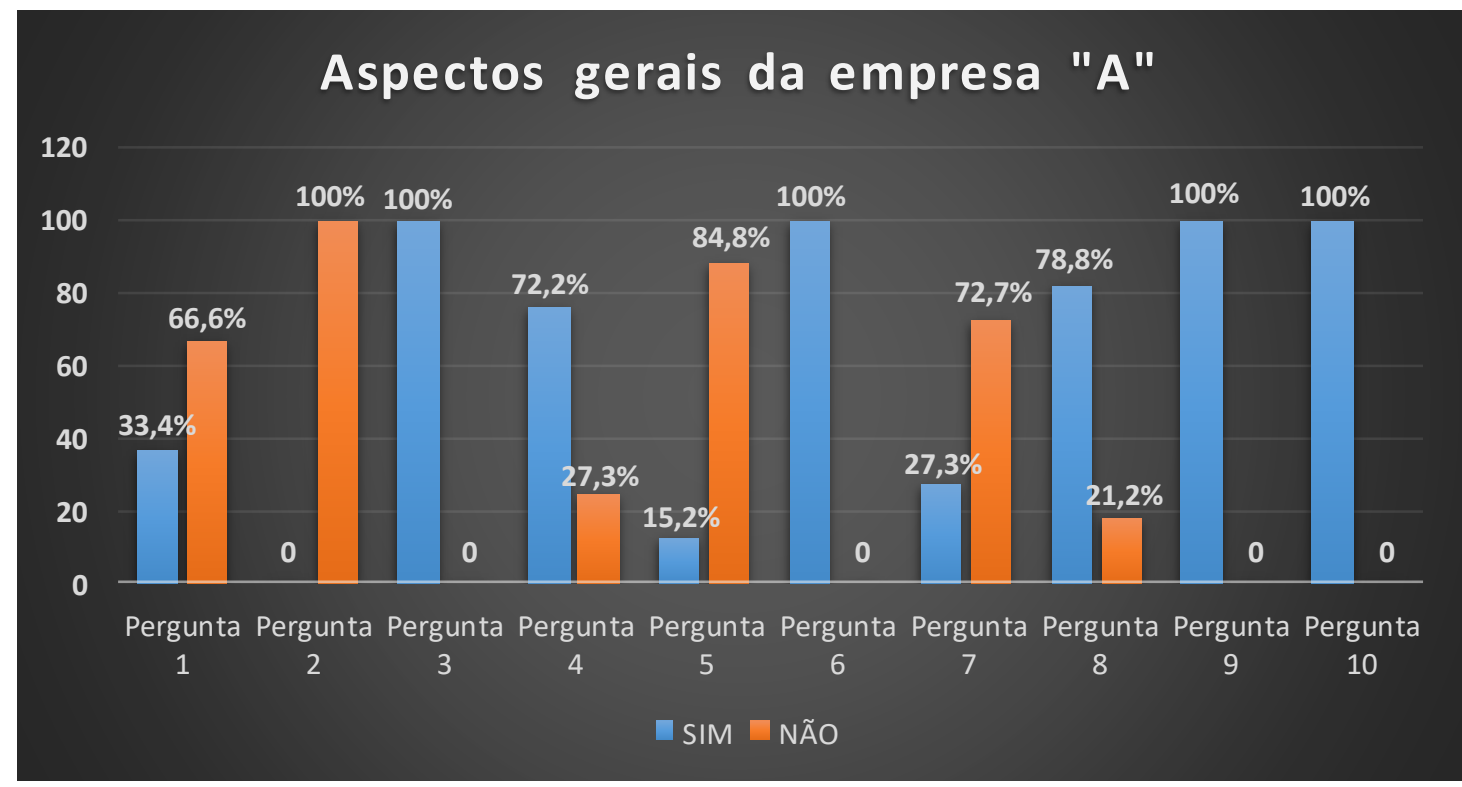

Figura 2: Resultado da percepção geral dos entrevistados da empresa "A".

Fonte: Dados produzidos pelo autor.

Na sexta pergunta, todos afirmaram observar passageiros destinando lixo em lugar impróprio, porém, dentre a descrição do local que foram destinados os resíduos, ficou entre o convés da embarcação e o rio; entretanto, a resposta que prevaleceu sobre o destino do resíduo foi o rio. Na sétima pergunta, $72,7 \%$ dos funcionários não chama a atenção e não interfere ao observar passageiros na embarcação destinando resíduos em lugar impróprio, apenas $27,3 \%$ dos funcionários afirmou chamar a atenção e descreveu que esta atitude não foi orientação por parte da empresa.

$\mathrm{Na}$ oitava pergunta, $78,8 \%$ dos entrevistados afirmou saber das consequências ambientais e sociais causadas pela destinação incorreta dos resíduos, alguns se justificaram falando que, devido obter esse conhecimento, pararam de jogar resíduos nos rios. Na nona e na décima pergunta, todos os funcionários entrevistados afirmaram ser necessário trabalhar a EA com foco na gestão de resíduos com os funcionários e usuários do transporte na empresa, assim como todos afirmaram estarem fazendo a parte deles no combate à poluição dos rios.

\section{Empresa "B"}

A empresa foi fundada no Município de Breves no ano de 1998, atualmente trabalha com três embarcações que fazem rota pelas cidades de Belém, Curralinho, Breves, Melgaço e Portel. Os resíduos sólidos têm destino 
nas cidades de Belém, Breves e Portel. De acordo com a gerência da empresa, quando perguntada por meio de entrevista se a empresa segue uma legislação específica do município ou a PNRS foi respondido: "basicamente apenas a coleta seletiva, porém de maneira informal alguns catadores de materiais recicláveis tem permissão para recolher material de dentro do navio que seja do interesse dos mesmos"; também a empresa disponibiliza dentro das embarcações e nos portos, lixeiras seletivas no padrão estabelecidos pela resolução № 275 do CONAMA, que estabelece o código de cores para os diferentes tipos de resíduos, a ser adotado na identificação de coletores e transportadores, bem como nas campanhas informativas para a coleta seletiva (BRASIL, 2012). Entretanto, não funciona, pois, os passageiros não possuem o cuidado de destinar os resíduos nos seus respectivos cestos.

A empresa não possui nenhum projeto sobre EA e expõe achar importante trabalhar essa questão com os funcionários, para que haja uma mudança de mentalidade e disseminação de novas condutas, porém segundo a empresa, isso demanda tempo e na nossa região esse tempo está sendo perdido, sem que haja qualquer ação a respeito desse assunto. Quando a gerência da empresa menciona a falta de ação, está se referindo a SEMMA por não trabalhar essa questão no transporte hidroviário do Município. A gerência descreve que somente alguns passageiros fazem sua parte destinando os resíduos nos locais corretos, a justificativa para essa atitude segundo a gerência é: "a falta de materiais educativos dentro das escolas sobre a destinação correta do lixo e isso acaba promovendo o crescimento de uma geração sem compromisso com o bem estar do meio ambiente". Ainda de acordo com a gerência, os funcionários não são orientados a intervir quando observam os passageiros destinando resíduos no local incorreto, já que essa atitude nem sempre é bem vista pelos passageiros, portanto, para evitar atritos não há instrução para tal ação. Ou seja, por receio de perder os clientes tornase conivente com a atitude do passageiro: "a única orientação dada aos funcionários é que recolham o lixo abandonado incorretamente de dentro do navio".

Responderam ao questionário vinte e três funcionários da empresa "B", os resultados da coleta dos dados estão expostos na Figura 3.

No resultado da primeira pergunta do questionário, evidencia que a maioria dos funcionários entrevistados $(66,6 \%)$ não ouviu falar sobre EA no transporte hidroviário do município. Com relação à segunda pergunta, 96,9\% não tem conhecimento de projeto sobre EA realizado pela empresa. Os funcionários que afirmaram conhecer, quando perguntados informalmente, não souberam descrever nenhum projeto da empresa. No resultado da terceira pergunta, todos afirmaram que os cestos para o depósito de lixo da embarcação são de fácil acesso. Em relação à quarta pergunta, $72,2 \%$ assegurou ter conhecimento de como é feita a gestão de resíduos sólidos feita pela empresa. Na quinta pergunta, $84,8 \%$ negou ter jogado algum tipo de material, objeto nos rios e $15,2 \%$ garantiu que jogou e se justificou, revelando que teve essa atitude por "costume", alguns funcionários em conversa informal 
afirmaram que os funcionários que trabalham na cozinha das embarcações, destinam nos rios todos os resíduos resultantes de sua atividade e articularam: "agora é uma boa oportunidade de chamar atenção deles pra isso".

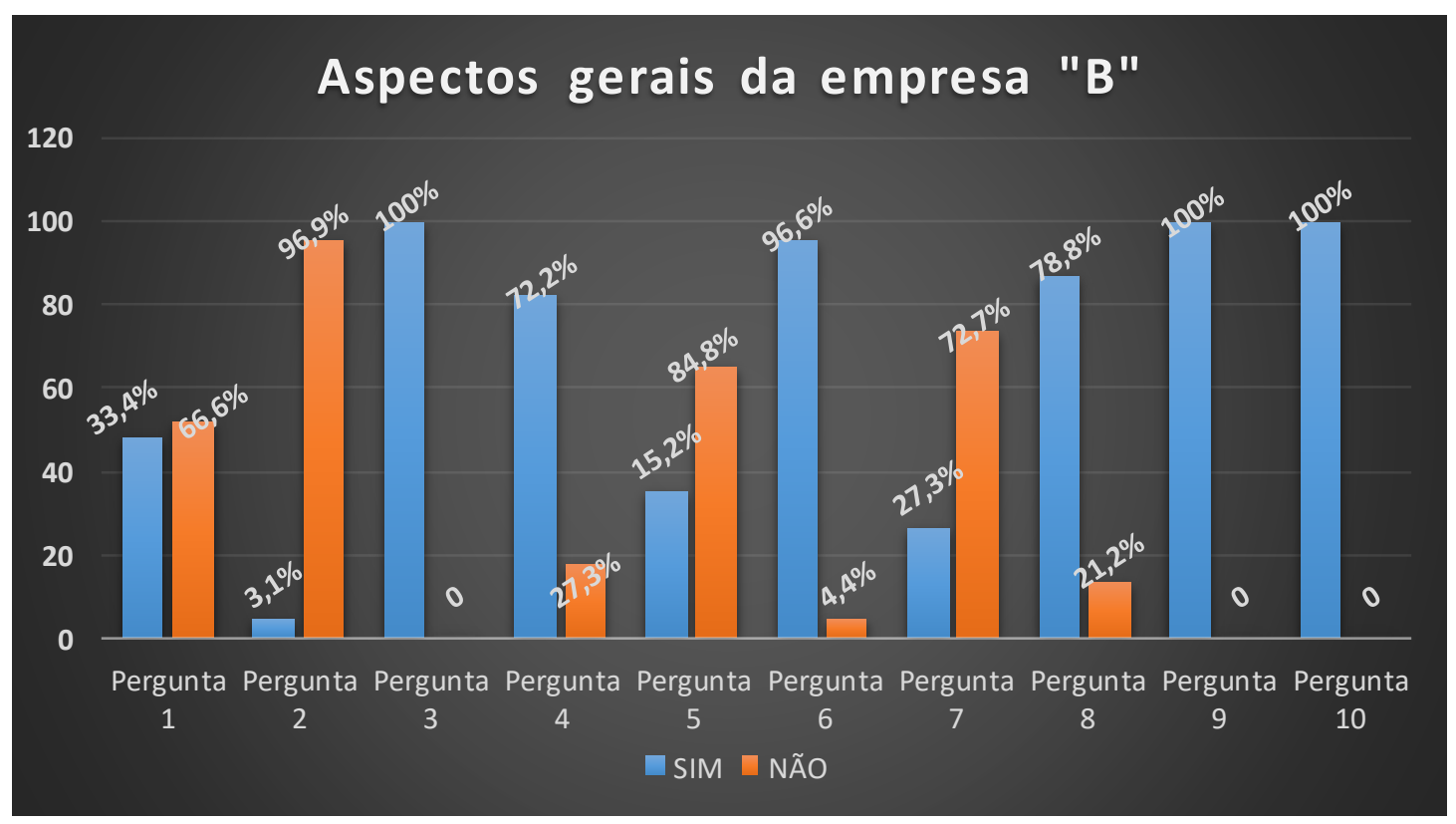

Figura 3: Resultado da percepção geral dos funcionários da empresa "B".

Fonte: Dados produzidos pelo autor.

No resultado da sexta pergunta, $96,6 \%$ dos funcionários entrevistados afirmou que observou passageiros destinando resíduos em local impróprio, dentre esses funcionários, a maioria descreveu que observou passageiros destinando os resíduos no rio. Na sétima pergunta, $72,7 \%$ não chama a atenção dos passageiros quando observa destinando resíduos em lugar impróprio, entretanto, $27,3 \%$ afirmou intervir na mesma situação, porém, a atitude dos funcionários não foi orientada pela empresa, mas sim, no curso para aquaviário e por conhecimento próprio. Na oitava pergunta, a maioria dos entrevistados $(78,8 \%)$ afirmou que tem conhecimento das consequências ambientais e sociais causadas pela destinação de lixo nos rios. Na nona e décima pergunta, todos os funcionários entrevistados afirmaram fazer sua parte e certificaram a necessidade de projetos com foco na gestão de resíduos e EA no transporte hidroviário.

\section{Empresa "C"}

A empresa foi fundada no ano de 1994 no Município de Breves, atualmente trabalha com uma única embarcação que faz rota pelas cidades de Belém e Breves, onde os resíduos sólidos têm destino nas respectivas cidades citadas anteriormente.

A gerência da empresa foi bastante sucinta ao responder as perguntas dirigidas à ela. Segundo esta, a empresa segue a Lei da PNRS para a 
preservação do meio ambiente e gestão dos resíduos sólidos. Possui também, projetos sobre EA com foco na gestão de resíduos sólidos com os funcionários, além disso, articula que possui projetos para tratar os resíduos sólidos, porém, não descreveu nada relacionado aos projetos citados. Ainda expôs ser importante trabalhar essas questões com os funcionários para diminuir a poluição, uma vez que, observou várias vezes as pessoas destinarem resíduos em local incorreto. De acordo com a gerência, os funcionários são orientados a intervir quando observarem os passageiros destinando resíduos em local incorreto.

Responderam ao questionário quinze funcionários da empresa "C". Menor amostra em comparação com as outras empresas participantes da pesquisa. Os resultados estão apresentados na Figura 4.

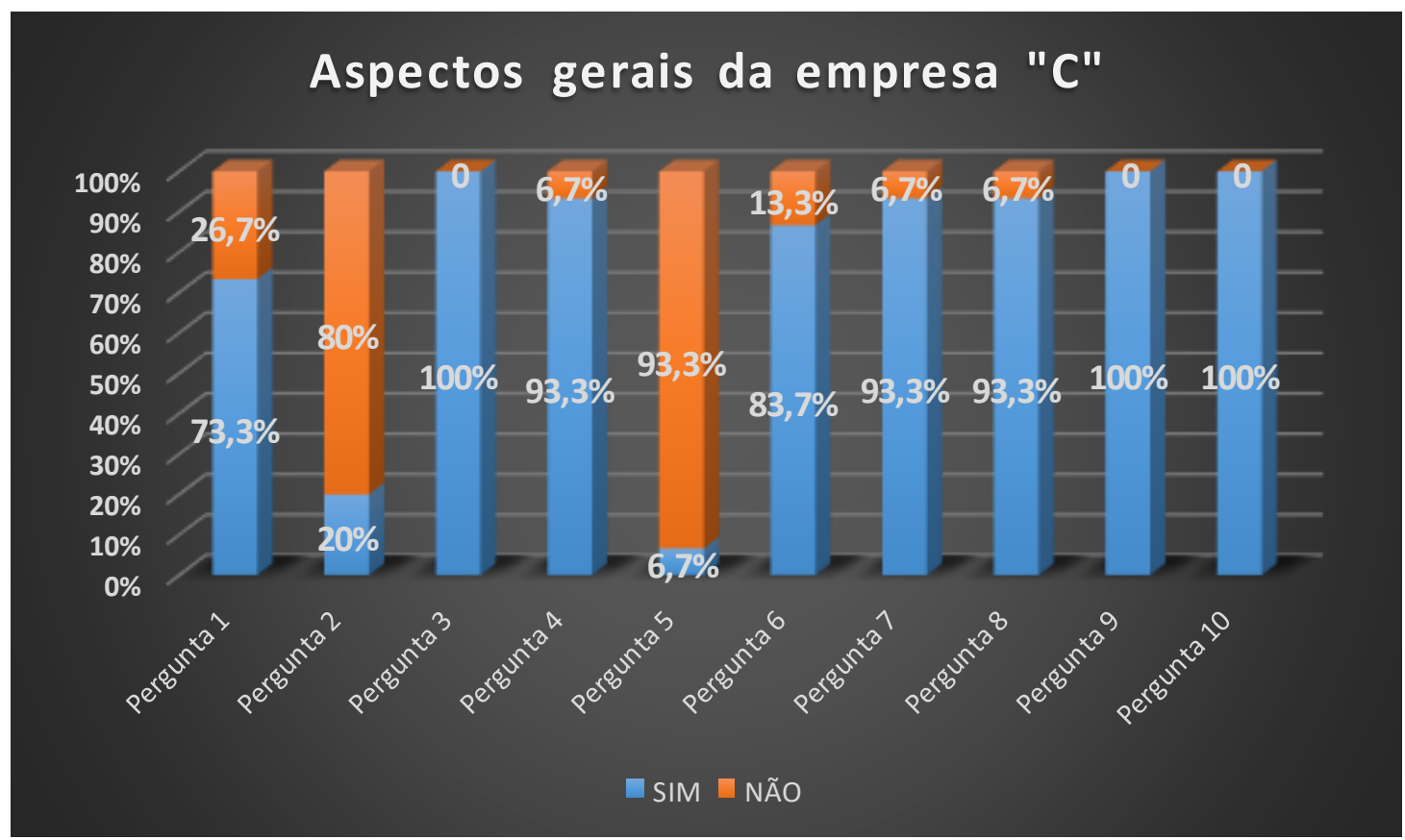

Figura 4: Percepção geral dos funcionários da empresa "B".

Fonte: Dados produzidos pelo autor.

Com relação à primeira pergunta, a maioria dos funcionários da empresa $(73,3 \%)$, afirmou ter ouvido falar sobre EA no transporte hidroviário do município. Segundo os funcionários, eles reconhecem a importância da EA, pois, através dela pode-se evitar a poluição do meio ambiente. Na segunda pergunta, apesar da gerência em entrevista afirmar que a empresa possui projeto sobre EA com foco na gestão de resíduos, $80 \%$ dos funcionários, ou seja, a maioria dos entrevistados não tem conhecimento desse projeto. Os que afirmaram conhecer, em conversa informal, não souberam descrevê-lo, logo, não pôde-se afirmar a veracidade do projeto citado pela falta de informação sobre o mesmo. Com relação à terceira pergunta, todos os funcionários afirmaram que os cestos destinados ao depósito de lixo são de fácil acesso e 
esclareceram "os lixeiros não são a justificativa para jogarem os lixos no rio ou no convés do navio, porque muitas vezes o lixeiro está do lado e a pessoa prefere jogar no rio ou no convés do navio".

Em relação à quarta pergunta, a maioria dos funcionários $(93,3 \%)$, afirmou ter conhecimento de como é feita a gestão de resíduos e descreveu em conversa informal que os resíduos são retirados do navio e depositados para a espera do carro coletor de lixo. No resultado da quinta pergunta, 93,3\% dos funcionários entrevistados, negou ter jogado algum tipo de resíduo no rio durante as viagens. Na sexta pergunta, $83,7 \%$ dos entrevistados, afirmou observar passageiros destinando lixo em local inadequado, descreveu então, que o local onde os passageiros destinavam os resíduos era o convés do navio e o rio.

Com relação ao resultado da sétima pergunta, 93,3\% afirmou intervir, por exemplo, chamar a atenção de passageiros quando observaram os mesmos destinando resíduos nos rios ou no convés do navio. Segundo os funcionários, a atitude não foi orientação por parte da empresa e sim por seus conhecimentos das consequências causadas através dessa atitude. Na oitava pergunta, 93,3\% afirmou ter conhecimento das consequências ambientais e sociais causadas pela destinação de lixo nos rios.

Os resultados da nona e décima pergunta foram que todos os funcionários afirmaram achar importante trabalhar com mais ênfase por parte da empresa a EA com foco na gestão de resíduos com funcionários e passageiros e afirmam também estar fazendo sua parte para não poluir os rios.

\section{SEMMA e a Gestão de Resíduos Sólidos dos Portos}

A Secretaria municipal de Meio Ambiente por meio de entrevista, esclareceu que não tem registro da existência de lei específica do município direcionada às empresas de navegação sobre a preservação do meio ambiente hídrico. De fato, não existe uma lei específica do município, entretanto, existe o Plano Municipal Integrado de Resíduos Sólidos aprovado por meio do Decreto № 056 em 2012, que tem como objetivos e princípios a redução, o reaproveitamento, o gerenciamento adequado dos resíduos sólidos; a prevenção e o controle da poluição; a proteção e a recuperação da qualidade do meio ambiente e a promoção da saúde pública, assegurando o uso adequado dos recursos ambientais no Município. Entende-se então que, por meio da vigência do decreto os recursos hídricos seriam preservados, todavia não é o que acontece na realidade.

No referencial teórico deste trabalho foi citado o projeto "Proteção e Preservação dos rios e igarapés do Município de Breves", que segundo a SEMMA foi elaborado em 2017; porém, em estudo do projeto em questão, constatou-se que o mesmo foi elaborado no ano de 2013 sob a coordenação do então Secretário Municipal de Meio Ambiente, Sidiclei Barros Miranda. Em conteúdo, o projeto não apresenta resultados, por este motivo procurou-se o coordenador do projeto para se ter conhecimento de suas reais ações.

revista brasileira educação ambiental 
Segundo o senhor Sidiclei, o projeto teve somente duas ações durante sua coordenação, uma direcionada às embarcações de pequeno, médio e grande porte e outra ação feita para retirar os lixos da orla municipal.

A SEMMA relata em entrevista que realiza palestras, rodas de conversa junto a empresários e funcionários de empresas de navegação de pequeno, médio e grande porte sobre preservação dos recursos hídricos e gestão dos resíduos sólidos. No entanto, segundo os funcionários das empresas de navegação, esclareceram que essas ações não estão sendo realizadas pela SEMMA; a gerência de uma das empresas afirmou: "se teve alguma ação desse tipo nas empresas aqui do município eu particularmente não tenho conhecimento".

Segundo a SEMMA:

Trabalhar a orientação, conscientização, sensibilização com funcionários, proprietários e usuários do serviço de navegação é de fundamental importância para o real alcance de mudança de hábitos do cidadão, acreditamos que se sua equipe de funcionários estiver orientada e sensibilizada com a causa, terão empoderamento necessário para a mudança de suas práticas cotidiana, podendo assim cobrar, sensibilizar passageiros e disseminar a consciência ambiental de usuários do serviço de navegação.

Quando instigada sobre uma futura parceria para trabalhar a EA com foco na gestão de resíduos sólidos no transporte hidroviário do município, a SEMMA explica:

Afirmamos que é de interesse total da instituição contribuir para a preservação de recursos ambientais, sendo que entendemos e acreditamos que juntos, com a realização de trabalhos em parceria com outras instituições Municipais, Estaduais e Federais; além do envolvimento e participação direto da sociedade civil poderemos contribuir para a preservação geral do meio ambiente e com isso para melhor qualidade de vida da população, no hoje e nas futuras gerações.

Portanto, fazer parcerias em prol da preservação do meio ambiente é de suma importância para todos, pois com a união de instituições, órgãos municipais e participação da sociedade todos ganham, já que para se ter uma melhor qualidade de vida, precisa-se ter um ambiente ecologicamente equilibrado. 


\section{Conclusões}

Através do resultado da pesquisa, observa-se que os objetivos e metas apresentados pela PNRS ainda são um grande desafio no município e no transporte hidroviário. Percebe-se que as empresas não seguem a PNRS e nem mesmo têm conhecimento das leis municipais com relação à gestão de resíduos e EA. Logo, constatou-se que nenhuma das três empresas possue projetos para tratar os resíduos sólidos produzidos.

Dos funcionários participantes da pesquisa, 94,3\% não tem conhecimento de projeto sobre EA, apesar de uma das empresas ter afirmado em entrevista que possui, mas não descreveu e tão pouco os funcionários não tem conhecimento do projeto.

No Plano de Gestão Ambiental do Município de Breves, pode-se ler, que "é instrumento de gestão ambiental a Educação Ambiental"; entretanto, de acordo com os resultados da pesquisa apresentados, a EA não vem sendo trabalhada como deveria nos espaços informais, como nas embarcações de grande porte do Município, pois $52,1 \%$ dos funcionários entrevistados afirmou não ter ouvido falar sobre EA no transporte hidroviário.

A poluição dos rios prejudica diretamente a saúde da população que depende da água para retirarem o alimento, para o consumo e afazeres domésticos. Além dos rios serem o acesso para transporte de pessoas e cargas que movimentam a economia do Município.

Logo, não cabe somente ao poder público, tão somente a população, todos são responsáveis de proteger e preservar o meio ambiente para assim preservar também a vida. Por isso, compreender a importância ambiental, social e econômica da preservação dos rios é o primeiro passo para sensibilização e mobilização de todos em relação à gestão de resíduos sólidos, pois os rios são como as ruas para os marajoaras, assim como precisa-se dos rios diariamente, eles precisam do cuidado de todos. Para que se tenha resultados efetivamente positivos em relação à gestão de resíduos, precisa-se ter ações conjuntas do município para instruir, fiscalizar e punir se for o caso, as empresas de navegação para colocar em prática nas embarcações por meio de novas condutas de seus funcionários e disseminação de novas ideias em relação à gestão de resíduos e da população por meio da sensibilização e mobilização com relação à gestão de resíduos, entretanto, isso só pode ser possível quando a EA for trabalhada em todos os âmbitos sociais, ou seja, ir além dos muros da escola.

As dificuldades foram inúmeras durante o levantamento de dados da pesquisa, pelo contexto ao qual a pesquisa foi realizada, pela falta de tempo da gerência das empresas e de alguns dos funcionários em função das atividades de trabalho, especialmente da tripulação das embarcações que inúmeras vezes se negaram a responder os questionários. Porém foi necessário adequar-se à realidade e investir em novas metodologias para tornar este trabalho autêntico. Além disso, para se chegar as informações necessárias precisou-se consultar documentos dos órgãos municipais que por muita insistência foram cedidos.

revista brasileira educação ambiental 
Quando pensado neste trabalho, a ideia inicial seria fazer um diagnóstico do tema em questão e em seguida formular um projeto objetivando a preservação dos rios, pois acredita-se que, para a implantação de um projeto, precisa-se conhecer inicialmente a realidade observada, fazer um profundo diagnóstico para assim, no final, avaliar as necessidades e diante delas, planejar e pôr em prática ações que atendam às necessidades. Essa é a justificativa para o projeto citado não fazer parte dos objetivos deste trabalho neste momento. Entretanto, através do resultado da pesquisa observou-se que o projeto já existe, porém, não é posto em prática como deveria. Diante desse cenário, pretende-se executar o projeto, em parceria com a SEMMA, junto às empresas que aceitarem e perceberem a necessidade do mesmo, adaptando-o às necessidades das empresas, observadas a partir dos resultados deste trabalho, para de fato o projeto ser funcional.

\section{Agradecimentos}

Aos gerentes e funcionários das empresas que possibilitaram o acesso aos dados da pesquisa. A coordenação do Campus Universitário do MarajóBreves, pelo apoio financeiro à pesquisa; à Universidade Federal do Pará, por tornar possível o desenvolvimento deste trabalho e a obtenção da graduação de um dos autores.

\section{Referências}

ABNT. Classificação de resíduos sólidos. NBR 10.004:2004. Rio de Janeiro. 71p. Disponível em: <http://analiticaqmcresiduos.paginas.ufsc.br/files/2014/07/ Nbr-10004-2004-Classificacao-De-Residuos-Solidos.pdf>. Acesso: 5 jan. 2018.

AZEVEDO, M; 2007. Plano de gerenciamento de resíduos sólidos em portos fluviais (Companhia Docas do Pará).

BRASIL. Lei № 9.795, de 27 de abril de 1999. Política Nacional da Educação Ambiental. Brasília. Disponível em: <http://www.planalto.gov.br/ccivil 03/leis/ L9795.htm>. Acesso em: 8 jan. 2018.

BRASIL. Programa Nacional de Educação Ambiental - ProNEA. 3a ed. Brasília 2005. Ministério do Meio Ambiente. Disponível em: <http://www.mma. gov.br/estruturas/educamb/ arquivos/pronea3.pdf>. Acesso em: 26 ago. 2017.

BRASIL. Resolução n 2190 - ANTAQ, de 28 de julho de 2011. Disponível em: $<$ http://www.codesa.gov.br/scriptcase/file/doc/codesa arquivos/ANTAQ.pdf>. Acesso em: 5 jan. 2018.

BRASIL. Resoluções do CONAMA. Edição especial. Brasília, 2012. Disponível em: <http://www.mma.gov.br/port/conama/processos/61AA3835 /LivroConama.pdf>. Acesso em: 18 dez. 2017.

BRASIL. Política Nacional de Resíduos Sólidos [recurso eletrônico]. $2^{\mathrm{a}}$ ed. Brasília, 2012, 73p. Disponível em: <http://fld.com.br/catadores/pdf/politica residuos solidos.pdf $>$. Acesso em: 10 dez. 2017.

Revbea, São Paulo, V. 14, № 1: 222-244, 2019. 
BRASIL. Decreto № 056, de 31 de Julho de 2012. Plano Municipal Integrado de Resíduos Sólidos de Breves. Regulamentada a Lei Federal № 12.305, de 02 de agosto de 2010, que dispõe sobre a Política Nacional de Resíduos Sólidos. Breves-PA, 2012.

BRASIL, Lei № 2.247, de 10 de janeiro de 2012. Lei Ambiental do Município de Breves. Breves-PA, 2012.

DIAS, L.S.; LEAL, A.C.; JUNIOR, S.C. Educação Ambiental: conceitos, metodologias e práticas. $1^{a}$ ed. Tupã-SP: ANAP, 2016.

FERREIRA, A.B.H. Dicionário Aurélio ilustrado. Curitiba-PR: Positivo, 2008.

FONSECA, J.J.S. Metodologia da pesquisa científica. Fortaleza, 2002.

Disponível em: <http://leg.ufpi.br/subsiteFiles/lapnex/arquivos/files/Apostila METODOLOGIA DA PESQUISA\%281\%29.pdf>. Acesso em: 25 ago. 2017.

GERHARDT, T.E. \& SILVEIRA, D.T. Métodos de Pesquisa. $1^{\text {a }}$ ed. Porto Alegre-RS: Editora da UFRGS, 2009.

IBGE. 2016. Cidades: Pará, Breves estimativa da população. Disponível em: $<$ https://cidades.ibge.gov.br/brasil/pa/breves/panorama>. Acesso em: 25 ago. 2017.

LEONARDI, M.L.A. A Educação Ambiental com um dos instrumentos de superação da insustentabilidade da sociedade atual. In. CAVALCANTI, Clóvis. Meio Ambiente, desenvolvimento sustentável e políticas públicas (Org.). 4ª ed. São Paulo-SP: Cortez: Recife: Fundação Joaquim Nabuco, 2002.

LOUREIRO, C.F.; et al. Repensar a Educação Ambiental: um olhar crítico. São Paulo-SP: Cortez, 2009.

MARTINS, K.V.; MORE, R.F. A política nacional de resíduos sólidos e as perspectivas para o setor portuário. Anais do XXXII Encontro Nacional de Engenharia de Produção, Bento Gonçalves, 2012. Disponível em: $<$ http://www.abepro.org.br/biblioteca/enegep2012 TN STO 165962 20956.p df>. Acesso em: 15 jan. 2019.

MORAES, R. Uma tempestade de luz: a compreensão possibilitada pela análise textual discursiva. Ciência \& Educação, Porto Alegre, v. 9, n. 2, p. 191211, 2003.

PARÁ. Decreto Estadual, de 30 de julho de 2007. Plano de Desenvolvimento Territorial Sustentável do Arquipélago do Marajó, Belém-PA: 2007. Disponível em: $<$ http://www.mi.gov.br/c/document library/get file?uuid= 9408a880-6ec04be0-9cb7-feb01c4a6256\&groupld=24915>. Acesso: 25 ago. 2017.

PREFEITURA MUNICIPAL DE BREVES, 2011. Plano Diretor Participativo do Município de Breves 2011-2020. Breves-PA. 62p.

PREFEITURA MUNICIPAL DE BREVES, 2012. Plano Ambiental Municipal. Breves-PA. 33p. 
REGUEIRA, T.M.; GUENTHER, M. Educação Ambiental aplicada à gestão de resíduos sólidos no transporte hidroviário urbano. Educação Ambiental em Ação, n. 4, 2014.

SANTANA, W.A. Proposta de diretrizes para planejamento e gestão ambiental do transporte hidroviário no Brasil. 2008, 277f. Tese - Departamento de Engenharia Naval e Oceânica, Escola Politécnica da Universidade de São Paulo. Disponível em: <https://www.teses.usp.br/teses/disponiveis/3/3135/tde31032008-164910/publico/apresentacao pretexto geral.pdf>. Acesso em: 26 ago. 2017.

SILVA, C.C. Coleta seletiva de resíduos sólidos urbanos: avaliação qualitativa do que pensa o cidadão no bairro Santa Terezinha, em Juiz de Fora - MG. 2014, 65f. TCC - Faculdade de Engenharia Ambiental e Sanitária, Universidade Federal de Juiz de Fora. Disponível em: <http://www.ufjf.br/engsanitariae ambiental/files/2014/02/TCC-Camila-Cortes-da-Silva.pdf>. Acesso em: 15 jan. 2019.

SILVA, A.M. Educação Ambiental e sua relação com atitudes, valores e comportamentos ambientalmente responsáveis. Anais XXXVIII Encontro da ANPAD. Rio de Janeiro, 2014. Disponível em: <http://www.anpad.org.br/ admin/pdf/2014 EnANPAD ESO1359.pdf>. Acesso em: 08 jan. 2018.

SILVA, E. Educação Ambiental: Lixo urbano de problema a possibilidades. 2015, 21f. TCC - Curso de Especialização Educação em Direitos Humanos, Universidade Federal do Paraná. Disponível em: $<$ https://acervodigital.ufpr.br/bitstream/handle/1884/42296/R\%20-\%20E\%20\%20EDINA\%20DA\%20SILVA.pdf?sequence $=1$ \&isAllowed $=\mathrm{y}>$. Acesso em: 17 jan. 2019.

VALLE, C.E. Qualidade Ambiental: O desafio de ser competitivo protegendo o meio ambiente. São Paulo: Pioneira, 1995. 